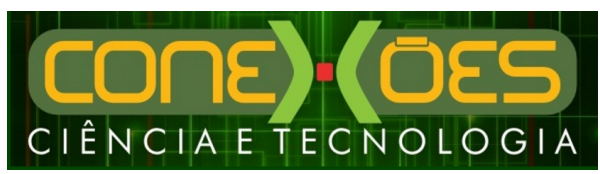

\title{
PLANEJAMENTO E EXPANSÃO DO TURISMO NO LITORAL DO MARANHÃO
}

\author{
CARlos Rerisson Rocha da COSTA \\ Universidade Estadual do Piauí - UESPI \\ $<$ rerissoncosta@yahoo.com.br> \\ DOI: $10.21439 /$ conexoes.v11i5.1290
}

\begin{abstract}
Resumo. No Brasil, onde a atividade turística é desenvolvida prioritariamente nos espaços litorâneos, a expansão do turismo sobre os espaços periféricos tem avançado na porção norte do litoral do país, extrapolando áreas em que pesados investimentos e diversificados instrumentos de planejamento vêm sendo executados desde a década de 1980. Nesse processo, o litoral do Maranhão passa a ser alvo das políticas de turismo, de investimentos públicos e privados, abrigando também as contradições associadas a essa atividade. Os planos estatais aparecem assim como instrumentos que impulsionam a apropriação desses espaços pelo turismo, alterando os usos do território. O presente artigo apresenta uma análise da expansão do turismo no litoral do Maranhão, evidenciando o papel dos planos de turismo como indutores dessa expansão no litoral do estado. Para a elaboração do presente artigo foram realizadas atividades de pesquisa bibliográfica e documental, a partir das quais se verificou que o litoral do Maranhão passa a figurar como espaço aberto ao turismo a partir da indução promovida nos planos estaduais dedicados a esta atividade, com destaque para as duas edições do Plano Maior. Tais instrumentos de planejamento apresentam o Maranhão como nova possibilidade para a expansão do turismo, como estoque de território para o qual passam a induzir um processo de incorporação para o lazer, com destaque para o seu litoral, tornando-se alvo de investidores que contam com crédito público, além de incentivos fiscais e financeiros, atuando diretamente em empreendimentos turísticos ou alimentando um amplo processo de cunho especulativo.
\end{abstract}

Palavras-chaves: Litoral; Turismo Litorâneo; Plano Maior.

\begin{abstract}
The expansion of tourism over peripheral areas in Brazil, where touristic activities are mainly developed on coastal areas, has advanced in the north part of the coast, beyond the areas receiving large investments and planning since the 1980s. During this process, tourism policies, public and private investments, and the contradictions associated with these activities have been present on the coast of Maranhão. Therefore, the state plans are instruments pushing the appropriation of these areas by tourism, changing the way this territory is used. This work presents an analysis of the tourism expansion on the coast of Maranhão, highlighting the roles of touristic plans as inducers of this expansion. Bibliographic and documentary researches showed that the coast of Maranhão became an open area for tourism after state plans were dedicated to this activity, especially the two editions of Plano Maior. Such planning instruments present Maranhão as a new possibility for the expansion of tourism, as a stock of territory to which they induce an incorporation process for leisure, especially the coast, being targeted by investors using public funding, besides fiscal and financial incentives to act directly on touristic enterprises or feed a speculation process.
\end{abstract}

Keywords: Coast; Coastal Tourism; Plano Maior.

\section{INTRODUÇÃO}

O litoral tem se destacado enquanto espaço destinado para o turismo desde os primórdios dessa atividade, em- bora isso se acentue no último século, tornando os espaços litorâneos lócus de processos marcadamente conflituosos. O turismo, que aparece como atividade de des- 
taque a partir da segunda metade do século XX, passando a ser adotado em países tropicais situados na periferia do capitalismo industrial como uma "alternativa econômica", transforma o lazer em mercadoria e intensifica a transformação dos espaços litorâneos nesses países.

No Brasil, onde a atividade turística tem sido desenvolvida prioritariamente associada ao litoral, a expansão do turismo tem avançado na porção norte do litoral do país, extrapolando áreas em que pesados investimentos e diversificados instrumentos de planejamento vêm sendo executados desde a década de 1980, como o litoral da região Nordeste.

A expansão do turismo se dá na busca por novos lugares para apropriação, fazendo da exploração dos recursos turísticos o meio pelo qual são transformados espaços em objetos de consumo para o lazer. Nesse sentido, os espaços periféricos tornam-se lócus de novas possibilidades para a expansão do turismo, induzido enquanto atividade hegemônica a esses espaços a partir de mecanismos estatais de planejamento alicerçados por incentivos fiscais e financeiros. Os planos aparecem então como o instrumento que impulsiona a apropriação desses espaços pelo e para o turismo, alterando os usos do território, produzindo nova materialidade e/ou possibilitando novos arranjos especulativos.

Inserido nesse contexto, o litoral do Maranhão passa a ser alvo das políticas de turismo, na busca por receber investimentos públicos e privados, abrigando também as contradições associadas a essa atividade. Os planos estatais aparecem assim como instrumentos que impulsionam a apropriação desses espaços pelo e para o turismo, alterando os usos do território. Nesse processo o litoral do Maranhão se estabelece como uma fronteira de expansão do turismo litorâneo e uma nova possibilidade para a acumulação de capital a partir dessa atividade (COSTA, 2015).

No presente artigo analisa-se a expansão do turismo no litoral do Maranhão, evidenciando o papel dos planos de turismo como indutores desse processo no do litoral do estado. Para isso, são apresentados elementos para a compreensão da expansão do turismo no estado, destacando os principais planos de turismo elaborados para o Maranhão, dentre os quais se sobressaem as duas edições do Plano Maior, executados a partir do início do século XXI.

A elaboração do presente artigo se baseou em atividades de pesquisa bibliográfica e documental, sendo parte de reflexões realizadas em nossa tese, desenvolvida de 2011 a 2015. A partir de tais procedimentos se verificou que o litoral do Maranhão passou a figurar como espaço aberto ao turismo a partir da indução pro- movida nos planos estaduais de turismo, com destaque para as duas edições do Plano Maior. Tais instrumentos de planejamento apresentam o Maranhão como nova possibilidade para a expansão do turismo, como estoque de território para o qual passam a induzir um processo de incorporação para o lazer, com destaque para o seu litoral, que se torna alvo de investidores agraciados com crédito público e outros incentivos. Trata-se, então, das bases da constituição do litoral do maranhão como a fronteira de expansão do turismo litorâneo na periferia do Brasil.

\section{O TURISMO NO MARANHÃO}

De modo geral, no Brasil, quando se fala do Maranhão logo se costuma lembrar do bumba meu boi, dos Lençóis Maranhenses e de José Sarney, figura política que conduz sua oligarquia há mais de quatro décadas no estado. Com exceção de José Sarney e sua "trajetória política", os outros dois elementos estão diretamente associados ao turismo (enquanto Sarney e sua oligarquia aparecem como elementos ocultos, da gestão, reunidos nos gabinetes e nos palácios). O bumba meu boi é escolhido como manifestação folclórica da cultura local a ser apropriada como atrativo turístico desde a década de 1970; os Lençóis Maranhenses tornam-se Parque Nacional, apresentados equivocadamente como um deserto repleto de lagoas no Nordeste do Brasil 1 , passando a ser promovido como paradisíaco destino turístico, desde os folders até as telenovelas.

Essa associação à imagem turística do Maranhão não se dá sem motivos. O Estado busca investir nas últimas duas décadas na divulgação de seus destinos, ampliação das infraestruturas necessárias à atividade e na elaboração de instrumentos para a indução da expansão do turismo, na tentativa de tornar seu território também um espaço para o uso turístico, perseguindo os resultados alcançados em estados como o Ceará, o Rio Grande do Norte, o Pernambuco e a Bahia. Tais esforços e a imagem produzida, entretanto, destoam da realidade social encontrada em seu território.

Embora ainda ocupe posição tímida no ranking dos destinos turísticos do país, a expansão da atividade turística se evidencia não só empiricamente, mas também a partir de dados que indicam o que é possível constatar in loco. O crescimento, no período de 2008 a 2013, de $63 \%$ no número de agências de turismo (127 em 2008

\footnotetext{
${ }^{1}$ Os Lençóis Maranhenses se configuram como um campo de dunas com características bastante particulares estabelecidas a partir da conjugação de processos de transporte e acumulação de sedimentos, associados à dinâmicas eólicas, à correntes marítimas e ao regime pluvial. Tais características diferenciam fundamentalmente os Lençóis Maranhenses de um deserto.
} 
e 207 em 2013) e de $181 \%$ na quantidade de meios de hospedagem (55 em 2008 e 155 em 2013) figura como bom indicativo de tal processo ${ }^{2}$, estando a distribuição de tais elementos concentrada majoritariamente no litoral do estado (MARANHÃO, 2012, p. 20-22).

Embora o crescimento do número de embarques e desembarques em voos domésticos tenha crescido no país ao longo desse período por uma série de outros motivos, o acréscimo de $126,5 \%$ e $123 \%$, respectivamente, nos números de desembarques e embarques deste tipo no período de 2008 a 2012 também pode ser utilizado como um indicador do aumento da procura do estado do Maranhão como destino turístico 3

Os dados disponíveis apontam um relevante crescimento na entrada de turistas no Maranhão de 2000 a 2010: de 520.128 para 2.519.000 turistas, mesmo apresentando período de queda associado ao contexto de crise econômica internacional nos anos de 2008-2009 (MARANHÃO, 2012, MARANHÃO, 2014) (Gráfico $\left.1\right|^{4}$. Nesse processo o turismo responde por cerca de $5 \%$ do PIB do estado, gerando receita aproximada de R\$ 2 bilhões ao ano (MARANHÃO, 2012).

Gráfico 1: Entrada de turistas no Maranhão, 2000-2010

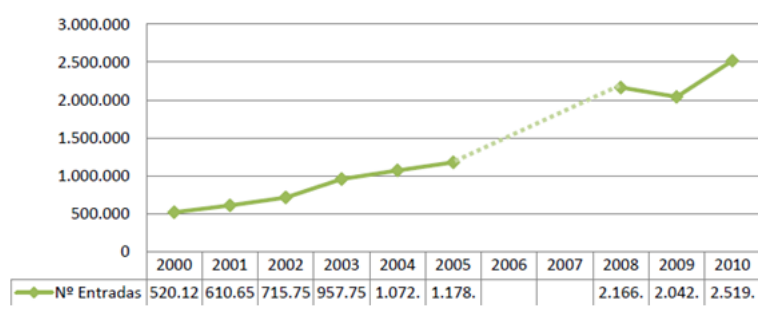

Fonte: Costa (2015)

Esse cenário tem suas raízes, entre outras coisas, na

${ }^{2}$ Consideramos aqui apenas os meios de hospedagem e as agências de viagem cujos dados encontram-se disponíveis nos Anuários Estatísticos EMBRATUR e nos Anuários Estatísticos de Turismo, de 2005 a 2014.

${ }^{3}$ Sabe-se da limitação do uso dos números de embarque e desembarque como indicador de fluxos turísticos, sobretudo no que diz respeito ao objeto de estudo em questão, cujos fluxos muitas vezes derivam de outros destinos regionais por via terrestre. Entretanto, acreditamos que tal dado possui relevância tendo em vista que, em pesquisa realizada pela Setur-MA em 2011, 58,6\% dos passageiros que desembarcaram no aeroporto de São Luís eram turistas e não residentes (MARANHÃ 2011).

${ }^{4}$ Os dados disponíveis apresentam descontinuidade temporal, com ausência de indicadores relativos à entrada de turistas no estado para os anos de 2006 e 2007. Em relação aos dados estatísticos referentes ao turismo no Maranhão, cabe destacar sua insuficiência e inconsistência. O próprio Plano Maior 2020, instrumento de planejamento do turismo atualmente em execução, ressalta esse problema, apontando que "as estatísticas disponíveis atualmente são inadequadas e insuficientes para dimensionar os fluxos turísticos" no estado e em seus polos (MARANHÃO 2012 p. 14) indução estatal efetivada a partir de um conjunto de órgãos e instrumentos de planejamento, alocação de recursos e incentivos aos investimentos na atividade, tudo articulado às estratégias estatais pensadas na esfera federal e destinadas a ações em escalas nacional, regional e/ou local. O desenvolvimento do turismo no Maranhão e sua configuração da maneira em que se encontra na atualidade, em que seu litoral é colocado como uma fronteira de expansão para o turismo, passa por um acúmulo histórico de iniciativas de planejamento, incluindo ações exitosas e equívocos, desmandos, má aplicação de recursos públicos, problemas de gestão, descontinuidade nas ações planejadas etc.

Assim como no âmbito federal, as políticas de turismo elaboradas e conduzidas pelo poder público no estado do Maranhão têm início tardiamente, marcadas por lento processo de sistematização que acompanha as reverberações regionais do avanço da importância da atividade turística no país e no mundo.

Somente na década de 1960 é criado o primeiro órgão estadual de turismo no Maranhão. Embora ainda em 1943 o governo do estado tenha feito a primeira menção oficial à atividade, quando da liberação de recursos para a construção do Palácio do Comércio em São Luís, onde viria funcionar o Hotel Central, é com a criação do Departamento de Turismo e Promoções do Estado do Maranhão, em 1962, que o governo estadual dá início à estrutura de "planejamento da atividade" (MARANHÃO, 1982; LOBATO, 2001).

Instituído em dezembro de 1962, o referido departamento tinha a atribuição de assessorar o governo do estado em relação ao turismo, visando planejar e coordenar atividades destinadas ao seu desenvolvimento, estudar e propor a criação de recursos para o fomento da atividade, apresentar planos que visassem dotar o estado de equipamentos turísticos - com destaque para os hotéis, registrar o patrimônio estadual e promover sua proteção, realizando ainda sua divulgação. Ressalta com isso o governo estadual a necessidade de investir, conhecer, divulgar, sem, contudo, apresentar efetivamente medidas sistematizadas para tanto. O conhecimento do território aparece como necessidade para que seja posto à disposição do uso turístico, seus lugares tornados destinos turísticos, verdadeiras mercadorias.

Institui também em 1962, no intuito de subsidiar financeiramente tais atividades, o Fundo Especial para o Desenvolvimento do Turismo, a ser mantido com a cobrança de $0,5 \%$ sobre "cotas de hotéis, ingressos de teatros e outros espetáculos para diversões públicas" e sobre a receita de empresas prestadoras de serviços turísticos (mais tarde, a partir de 1964, essa taxa viria a ser elevada para 10\%) (MARANHÃO, 1982, p. 05). 
As ações do Departamento de Turismo e Promoções do Estado do Maranhão ficaram bastante restritas à promoção do folclore estadual, reflexo direto da designação de Domingos Vieira Filho para a coordenação do referido órgão. Neste período, Domingos Vieira Filho ocupava também a diretoria do Departamento de Cultura do estado e, comandando os dois órgãos ao mesmo tempo, passou a atuar com o propósito de incentivar a cultura local (posição justificada por sua atuação já destacada como folclorista no Maranhão), não contemplando objetivos especificamente ligados ao turismo. Foram realizados concursos de manifestações culturais e folclóricas, como o bumba meu boi, além de elaborados guias turísticos e roteiros da cidade de São Luís (FERREIRA, 2007).

Ainda na década de 1960 foi instituído o Furintur - Fundo Rotativo de Incentivo ao Turismo, vinculado à Superintendência de Desenvolvimento do Maranhão - Sudema. De 1968 a 1973, ano em que foi extinto, o Furintur subsidiou a construção da sede do Departamento de Turismo, a instalação de um posto de informações turísticas, o cadastramento de grupos folclóricos, a confecção de material de divulgação turística, a inclusão do bumba meu boi no calendário turístico do Brasil (em 1971) e a inclusão de São Luís no roteiro de diversas operadoras de turismo no país. Continuaram, assim, centradas as ações em atividades culturais, inclinandose ainda a ação do Estado ao papel de divulgação com vistas ao favorecimento do setor hoteleiro (LOBATO. 2001).

É a Coordenadoria de Turismo e Cultura Popular, criada em 1971, que age no sentido de estabelecer um plano de desenvolvimento para a atividade no Maranhão, contratando para isso "um consórcio de duas empresas de consultoria, a ASTEL - Assessores Técnicos e a WIT - OLAF PROCHNIK - Arquitetura e Planejamento" (LOBATO, 2001, p. 82). O plano elaborado Plano de Desenvolvimento Turístico do Estado do Maranhão - apresentava seu potencial turístico, a infraestrutura disponível, os equipamentos e serviços turísticos, uma análise do mercado turístico para o Maranhão e seus impactos econômicos, além de indicações dos recursos para investimentos. No referido plano são propostas a criação de um Conselho Estadual de Turismo, da Empresa Maranhense de Turismo e de Órgãos Executivos municipais. Tais elementos comporiam um Sistema Estadual de Turismo que conduziria a formulação, coordenação e execução de uma política estadual dedicada à atividade turística (MARANHÃO, 1972). O planejamento se aperfeiçoa paulatinamente, mas seus resultados continuam irrisórios.

Afirma Lobato (2001) que, das ações propostas neste plano, quase nada foi executado, o que não difere em muito de outros tantos apresentados posteriormente. Sua elaboração centrada no corpo técnico das consultorias contratadas, desconsiderando a possibilidade de sugestões dos diversos segmentos interessados no desenvolvimento da atividade no estado, em muito limitaram os impactos da proposta. Reproduz-se ainda aí um tratamento dado ao planejamento turístico limitado a um aspecto promocional, permanecendo distantes proposições objetivas de enfrentamento às carências de infraestrutura e a produção de condições mínimas para o desenvolvimento da atividade.

Apesar disso, tal documento representa uma primeira sistematização da intenção do governo do estado em relação ao turismo. Anos mais tarde, em 1976, parte da estrutura proposta para o Sistema Estadual de Turismo viria a ser executada, com a criação do Conselho Estadual de Turismo e da Empresa Maranhense de Turismo - Maratur.

A Maratur foi instituída tendo como objetivos executar a política de turismo preconizada pelas distintas esferas de governo, observando as diretrizes fixadas pela Embratur e pelo Conselho Estadual de Turismo. Nesse sentido, foi proposta com o intuito de fomentar, no âmbito estadual, as atividades do turismo, mediante sua participação direta ou indireta, além de financiar, dentro de suas possibilidades orçamentárias, planos e programas que visassem o desenvolvimento da atividade no Maranhão. Aproximava-se assim de sua congênere nacional, a Embratur, capitaneando a posição de executora da política de turismo no estado.

Embora ainda perdurasse uma tendência ao destaque dos aspectos culturais/folclóricos no planejamento da Maratur, em 1980 é por ela proposto um Programa de Zoneamento do Estado do Maranhão, com vistas a conhecer o potencial turístico do estado e direcionar suas ações levando-se em conta o território. A partir da realização de um Inventário da Oferta Turística são definidas cinco zonas turísticas: Zona Histórico-Cultural, composta por São Luís, Alcântara, São José de Ribamar e Paço do Luminar; Zona dos Lençóis, formada pelos municípios de Cedral, Cururupu e Guimarães (portanto referindo-se à Ilha dos Lençóis e não aos Lençóis Maranhenses); Zona Litorânea do Artesanato, agrupando os municípios de Araioses, Tutóia e Barreirinhas; Zona dos Cocais, onde estavam Caxias e Timom; e a Zona dos Lagos, formada por Arari, Itapecuru-Mirim, Penalva, Pindaré, Santa Inês, Viana e Vitória do Mearim (Figura 1).

Destas zonas, apenas a primeira foi considerada como de efetivo desenvolvimento turístico, ficando as demais na condição de "zonas potenciais", fazendo com 
Figura 1: Mapa do Zoneamento do Estado do Maranhão (1980) Zonas Turísticas.

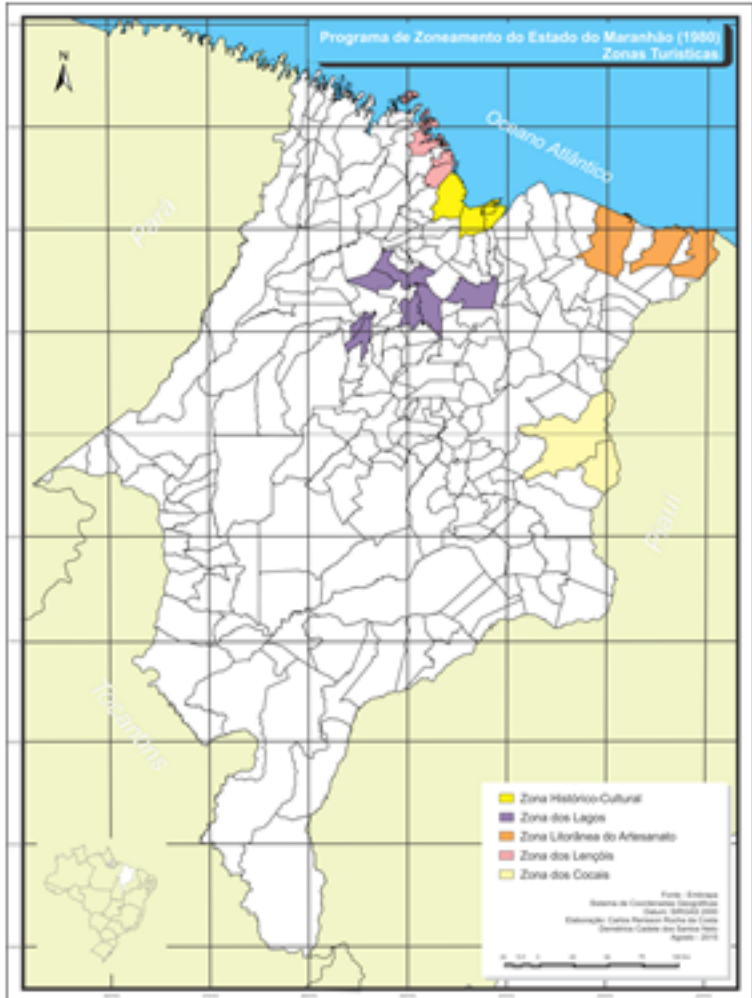

Fonte: Costa 2015

que as ações da política estadual de turismo fossem concentradas em São Luís (ou no eixo São Luís/Alcântara). Tal tendência só é alterada na década de 1990, quando passam a ser induzidos fluxos e investimentos turísticos para os municípios de Barreirinhas e Carolina, como parte do processo de expansão do uso turístico do território do Maranhão.

No contexto do Prodetur-NE, é elaborado pela Secretaria de Estado de Meio Ambiente e Turismo - SEMATUR, em 1993, o Prodetur-MA - Programa de Ação para o Desenvolvimento do Turismo no Maranhão. Tal programa tinha como propósito consolidar o estado como importante destino turístico nacional e internacional, seguindo os moldes da política regional em curso. Visava, para isso, induzir novos investimentos em infraestrutura, concretizando roteiros que permitissem elevar o tempo de permanência do turista no estado. Nesse sentido planejava ainda a promoção do turismo no Maranhão por meio de um programa de marketing, dando viabilidade à captação de recursos pretendida.

As ações propostas contemplavam apenas o mesmo eixo já centro das atenções da política de turismo estadual: o eixo São Luís/Alcântara . Destacam-se nesse processo a recuperação do Centro Histórico da capital, que viria a ser tombado como Patrimônio Histórico da Humanidade em 1997 pela Unesco, e a ampliação e reforma do aeroporto de São Luís (Aeroporto Internacional de São Luís - Marechal Cunha Machado).

No contexto do avanço do turismo no Nordeste do Brasil, processo no qual o Prodetur-NE tem grande peso, o litoral da região passa a se consolidar como destino turístico e a abrigar processos associados à transformação dos usos do território. Nesse cenário o governo do estado do Maranhão investe na elaboração de uma proposta de planejamento turístico capaz de induzir seu desenvolvimento e captar recursos disponíveis a partir das políticas federais em âmbito nacional e/ou regional. É nesse sentido que é estruturado o Plano de Desenvolvimento Integral do Turismo no Maranhão Plano Maior (MARANHÃO, 2000). Nesse plano é nitidamente priorizado o litoral como espaço para o uso turístico, ficando concentrada aí a maior parte de seus polos turísticos. Sua nova edição, o Plano Maior 2020 - Plano de Desenvolvimento Estratégico de Turismo do Estado do Maranhão, elaborada em 2010, prossegue com essa tendência, indicando ainda novos elementos de indução para a expansão da atividade (MARANHÃO, 2012). Compõem esses dois planos as principais políticas de turismo do estado do Maranhão, responsáveis pela indução da expansão do turismo em seu território e, de modo específico, em seu litoral.

\section{O PLANO MAIOR E O TURISMO NO LITO- RAL DO MARANHÃO}

Embora o Maranhão tenha estabelecido algumas medidas governamentais e efetuado a criação de órgãos dedicados ao planejamento do turismo a partir da década de 1960, é somente a partir da década de 1990 que o estado passa a contar com políticas mais sistematizadas voltadas à atividade turística e instrumentos de planejamento que expõem a intenção de expandir o uso turístico do território para além do eixo São Luís-Alcântara. Mediante as intenções de se colocar como espaço para o uso turístico e no anseio de captar recursos, como com a inserção do estado no Prodetur-NE e mais tarde no Proecotur, o governo do estado elabora o Plano Estadual de Turismo em 1995, reapresentado em janeiro de 2000 sob a insígnia de Plano de Desenvolvimento Integral do Turismo no Maranhão (chamado desde sua elaboração na década de 1990 de Plano Maior) (MARANHÃO. 2000, FERREIRA, 2007).

O Plano Maior, dividido em três etapas, a primeira dedicada a um Diagnóstico, a segunda à Estratégia de Desenvolvimento e a terceira ao Plano Operacional, apresenta o Maranhão ressaltando a condição "privile- 
giada" do estado quanto à sua localização, à diversidade de ecossistemas e belezas naturais, à presença de características do Nordeste e da Amazônia, ao seu extenso litoral, sua cultura e história. Propõe assim naturalizar aquilo que é fruto de opções políticas, lançando mão do que Moraes (2005) denomina de Ideologias geográficas, um discurso que veicula determinada visão do território reforçando suas "aptidões", apontando suas características como condutoras de seu "destino". Naturaliza-se assim as opções, escolhas dos grupos políticos e seus interesses, justificando ainda todos os conflitos derivados dos novos usos destinados aos territórios, já que é de se sua natureza ser um atrativo turístico: o que falta é "descobri-lo"!

Quando nos instrumentos de planejamento estadual do turismo, como o Plano Maior, é ressaltada a localização do estado como privilegiada no território nacional, destacando que seu ambiente "apresenta características do Nordeste, da Amazônia e do Cerrado”, dá-se as bases naturais mais gerais a que se associam os atributos territoriais apresentados como atrativos turísticos no referido instrumento de planejamento (MARANHÃO. 2000, p. 06). Paisagens eleitas como prioritárias para a exploração do turismo, constituindo-se discursivamente a base da localização dos polos turísticos propostos e sua composição cênica principa 5 Cachoeiras, chapadas, serras, lagos, cavernas, sítios arqueológicos, praias, rios e dunas fazem parte do arsenal de pontos de interesse vinculados às propostas de divisão do território em polos turísticos. As características do encontro do Nordeste com a Amazônia passam, desse modo, a compor também o rol de atributos utilizados para justificar a "potência" do Maranhão como destino turístico.

Proposto com a pretensão de criar uma imagem turística do Maranhão, o "produto Maranhão" e aumentar o fluxo turístico do estado, buscando estruturar-se com investimentos em infraestrutura e serviços públicos, hotéis, restaurantes e outros serviços turísticos, o Plano Maior regionaliza o território do Maranhão em 5 polos turísticos: Polo 1 - Histórico-Cultural, Polo 2 - Lençóis Maranhenses, Polo 3 - Delta do Parnaíba, Polo 4 - Reentrâncias Maranhenses, e Polo 5 - Águas, Cachoeiras e Chapadas (Figura 2), sobre os quais apresenta os recursos e atrativos turísticos, as formas de acesso e considerações quanto à infraestrutura, em

\footnotetext{
${ }^{5}$ Para maiores detalhes acerca da geodiversidade no território do Maranhão, Cf. Bandeira (2013).

${ }^{6}$ Os polos são formados pelos seguintes municípios: Polo 1: São Luís, Alcântara, Raposa, Paço do Lumiar e São José de Ribamar; Polo 2: Santo Amaro, Humberto de Campos, Primeira Cruz e Barreirinhas; Polo 3: Paulino Neves, Tutóia e Araioses; Polo 4: Cedral, Cururupu, Guimarães e Porto Franco do Maranhão; Polo 5: Imperatriz, Carolina e Riachão (MARANHÃO 2000 p. 13-14).
}

quase todos apontada como deficiente e encarada como um problema, destacando-se questões referentes ao saneamento básico, à coleta de lixo, à distribuição de energia elétrica e à pavimentação da malha viária. $\mathrm{O}$ transporte é apontado como um dos principais limitadores à atividade, frente ao relativo distanciamento ou mesmo isolamento dos destinos propostos. Além disso, a hospedagem na maior parte dos polos era apontada também como um problema, por sua baixa qualidade ou mesmo por sua inexistência.

Figura 2: Mapa de Polos Turísticos do estado do Maranhão no Plano Maior.

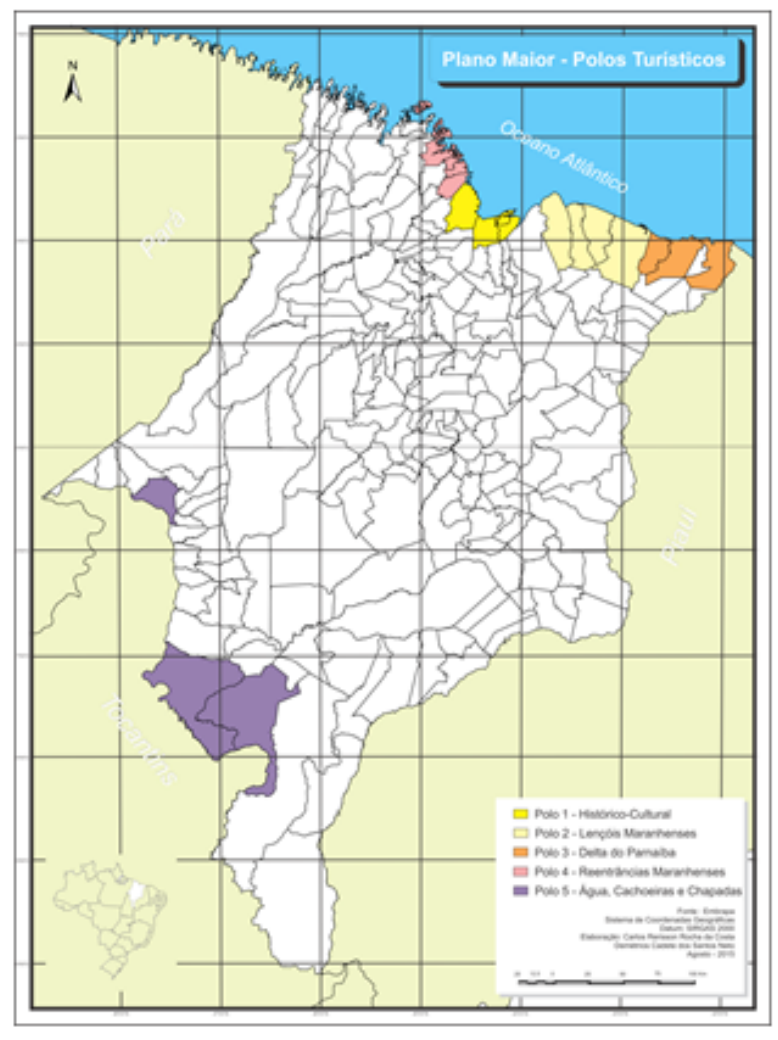

Fonte: Costa 2015

A distribuição dos cinco polos mencionados ressalta o caráter litorâneo adotado para a indução da atividade turística no Maranhão, seguindo uma tendência nacional e predominantemente regional, associada ao turismo de sol e praia. Dos cinco polos propostos no Plano Maior, apenas um não está situado no litoral (o Polo 5 - Águas, Cachoeiras e Chapadas), contemplando a região da Chapada das Mesas, no sul do estado, tendo destaque como atrativo o Parque Nacional da Chapada das Mesas criado em 2005 englobando área dos municípios de Riachão, Carolina e Estreito. Embora o apelo histórico-cultural apareça no planejamento que envolve São Luís, todos os municípios do polo são litorâneos e 
têm suas praias apresentadas como recursos turísticos. $\mathrm{O}$ fato de serem apresentados como principais recursos turísticos (chamados de potencial A) um conjunto de atrativos em que todos estão situados no litoral também reforça a tendência à indução do uso turístico dessa parcela do território.

O Plano Maior direciona a indução do turismo para o litoral alocando aí a maioria dos polos turísticos propostos no referido plano, com exceção do já mencionado polo ligado à Chapada das Mesas. As antigas zonas dos cocais e dos lagos - constantes na proposta de zoneamento elaborada pela Maratur na década de 1980 (Cf. Figura1 - não mais aparecem como áreas de interesse turístico para o Estado, refletindo a tendência ao turismo litorâneo que deriva do Prodetur-NE a partir da década de 1990, mas também vinculando-se à relativa pequena importância dada ao turismo pelas administrações locais nos municípios que compunham esses polos. Essa eleição dos lugares evidencia mais ainda o caráter político do uso turístico do território. Os atributos naturais e culturais apontados como justificadores das regionalizações continuam compondo a paisagem antes destacada como atrativa e potencial. Os agentes da indução e os destinos de interesse para os fluxos é que se alteram, configurando-se assim uma opção política situada no âmbito das relações de poder que marcam a vinculação Estado-Capital.

No Polo 1 - Histórico-Cultural são ressaltados o patrimônio cultural de São Luís e Alcântara, o atrativo religioso de São José de Ribamar e suas praias, assim como as praias de Raposa e Paço do Lumiar. O Polo 2 Lençóis Maranhenses é apresentado no plano como um espaço único, destacando a necessidade de se explorar o Parque Nacional dos Lençóis Maranhenses como recurso turístico. Em relação ao Delta do Parnaíba, que compõe o Polo 3, e ao Polo 4 - Reentrâncias Maranhenses são priorizadas suas potencialidades para o ecoturismo: no primeiro ressaltam seus manguezais e ilhas, no segundo sua "condição amazônica".

Todos esses polos são então apresentados como um segredo ainda a ser descoberto, dando a base para a elaboração da marca "Maranhão. O Segredo do Brasil" e mesmo para a campanha destinada aos veículos de imprensa intitulada Descubra nosso segredo. É preciso dizer que mais que esses "segredos" postos à venda a partir do Plano Maior, outros muitos dos segredos do Maranhão ainda relutam para não serem descobertos, ocultados nas relações que erguem o "Maranhão dinástico" (GONÇALVES, 2000, GONÇALVES, 2008) e reproduzem aqueles signos da morte de que nos fala Wagner Cabral, "decadência, violência e tradição" (COSTA 2006) (COSTA, 2006) compondo um enredo carregado de mitos políticos e um arsenal ideológico impulsionador da modernização no estado e seus conflitos que, comumente, têm produzido uma história escrita com sangue ao longo de décadas. Cabe dizer ainda que é durante a execução deste plano que os Lençóis Maranhenses passam a ser reconhecidos como destino turístico de destaque no Nordeste. Os municípios que compõem o polo e seus vizinhos passam a figurar como espaços de expansão da atividade turística. Durante sua execução são também realizadas intervenções no âmbito do Prodetur-NE e do Proecotur (em municípios do Polo 4 - Reentrâncias Maranhenses). Embora seus efeitos no campo da infraestrutura sejam tímidos se comparados aos projetos executados em outros estados do Nordeste do Brasil ligados ao Prodetur-NE, os fluxos turísticos se elevam, passando alguns pontos do estado a experimentar as dinâmicas associadas à inserção do turismo nesses espaços periféricos (aquecimento do mercado de terras e especulação imobiliária, alterações nas relações de trabalho e muitas vezes conflitos).

A promoção dos destinos se efetivou, embora com predominância dos chamados destinos indutores (São Luís, Barreirinhas e Carolina77. Investimentos foram realizados durante a primeira década do século XX, mesmo no contexto de crise internacional. O turismo continuou figurando entre as múltiplas estratégias estabelecidas pelo governo do estado do Maranhão para modernizar seu território e garantir a expansão da acumulação, dividindo espaço com os projetos de exploração mineral, o agronegócio, a indústria e o avanço no setor de serviços em geral.

Mesmo assim, embora elaborado no fim da década de 1990 e executado durante os anos 2000, este plano surtiu efeitos que parecem pequenos, sobretudo quando levados em consideração aspectos que ultrapassam os indicadores quantitativos (de fluxos de turistas, receita, etc.) e se volta para a transformação qualitativa da vida nesse território, marcado por péssimos indicadores sociais, deficientes serviços públicos e precária malha rodoviária. No sentido de seguir com o movimento de expansão da atividade turística no estado, a Setur-MA elabora um novo plano de turismo no ano de 2010.

Este novo plano foi intitulado Plano Maior 2020 Plano de Desenvolvimento Estratégico de Turismo do Estado do Maranhão, com a pretensão de planejar o desenvolvimento do turismo no estado por uma década. O plano foi construído em três fases (Fase 1 - Análise da situação atual, Fase II - Planejamento Estratégico e Fase III - Plano Operacional) visando fortalecer o tu-

\footnotetext{
${ }^{7}$ Embora o Ministério do Turismo aponte como destinos indutores no Maranhão apenas São Luís e Barreirinhas, em um rol de 65 destinos indutores no país, a Setur-MA inclui Carolina como um destino indutor em seu planejamento.
} 
rismo como uma das alternativas para o crescimento da economia do Maranhão. A partir do diagnóstico realizado e tomando em conta o fato de o Plano Maior ter ultrapassado suas metas em relação aos fluxos turísticos - prevista para 1,5 milhões de turistas em 2010, traz a indicação de linhas de atuação necessárias para alcançar novas metas de expansão (MARANHÃO, 2012).

O território do Maranhão é apresentado, como na primeira edição do Plano Maior, a partir de seus atributos naturais, com base em sua posição geográfica e nas características a ela relacionadas, como o encontro dos ecossistemas Amazônico e Cerrado. Tais características são apresentadas como "os mais efetivos determinantes do potencial turístico do Maranhão" (MARANHÃO, 2012, p. 59). As características do litoral, marcado pela forte presença de rios e mangues, o que confere às suas praias coloração distinta das demais da região (tendo aspecto barrento e não esverdeado ou azul como nos principais destinos do Nordeste) são apontadas como justificadoras para uma menor atratividade para o segmento sol e praia.

Com base nas potencialidades apresentadas, a SeturMA elaborou no Plano Maior 2020 uma nova regionalização para o território do Maranhão, reunindo 68 municípios de interesse turístico em dez polos: Polo São Luís, Polo Munim, Polo Parque dos Lençóis Maranhenses, Polo Delta das Américas, Polo Floresta dos Guarás, Polo Amazônia Maranhense, Polo Chapada das Mesas, Polo Cocais, Polo Lagos e Campos Floridos, Polo Serras, Guajajaras, Timbira e Kanela (Figura 3).

Estes polos estão segmentados em Polos Indutores (São Luís, Parque dos Lençóis Maranhenses e Chapada das Mesas), Polos Estratégicos (Floresta dos Guarás, Delta das Américas, Munim e Lagos e Campos floridos) e Polos de Desenvolvimento (Amazônia Maranhense, Cocais e Serras, Guajajara, Timbira e Kanela).

Tal distribuição hierárquica das categorias dos polos indica vetores de expansão da atividade que, embora não lineares, posicionam os municípios do Litoral Ocidental como espaços de expansão (Floresta dos Guarás como polo estratégico, em condição intermediária entre os polos indutores e os polos de desenvolvimento, classe em que se situa o polo Amazônia Maranhense), fundos territoriais para o turismo em vias de incorporaçã $\AA^{8}$. Os polos indutores são aqueles que apresen-

\footnotetext{
${ }^{8}$ Compreendemos aqui o conceito de fundos territoriais como espaços sem "uso hegemônico", onde o uso capitalista do território não é hegemônico ou não atende às necessidades de acumulação vigente no plano das relações capitalistas. Configuram-se, portanto, como uma espécie de estoque territorial para a expansão da acumulação de capital, embora possam conter usos não propriamente capitalistas ou apenas estarem sob domínio passível de apropriação. Tal pressuposto não exclui a existência de grupos sociais cujas relações de reprodu-
}

Figura 3: Mapa de Polos Turísticos do estado do Maranhão no Plano Maior 2020.

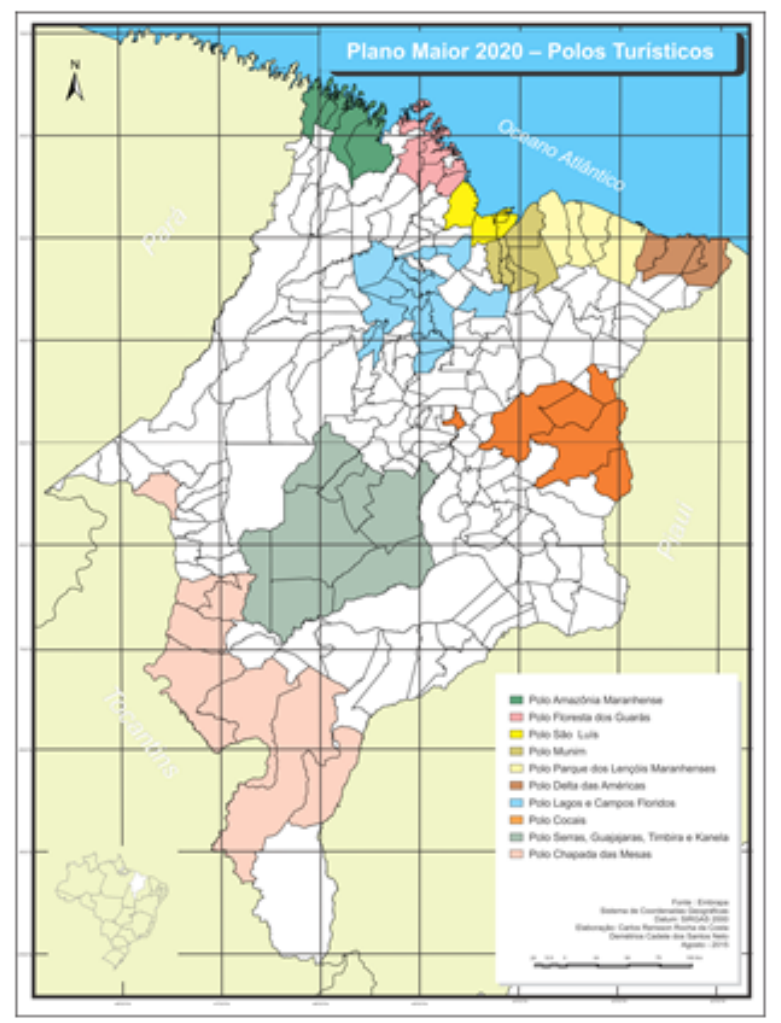

Fonte: Costa (2015).

tam "capacidade de obter a máxima rentabilidade a partir da melhor otimização da oferta atual e dos produtos existentes" em curto e médio prazos. Por sua vez, os polos estratégicos são considerados importantes para "a diversificação da oferta em médio prazo", tanto por seus potenciais quanto por questões de acessibilidade, enquanto os polos de desenvolvimento são apontados como áreas para investimentos a longo prazo, requerendo indução de investimentos e divulgação, porém "em cenários orçamentários limitados" (MARANHÃO. 2012, p. 184).

$\mathrm{Na}$ referida proposta retornam a figurar como áreas destinadas ao uso turístico do território a região da Baixada Maranhense e dos Cocais, sendo incluído ainda um polo vinculado à cultura indígena. Embora sejam propostos novos polos no interior do território, priorizase ainda o desenvolvimento do turismo no litoral, concentrando a maior parte dos polos turísticos no espaço litorâneo. Dos dez polos estabelecidos, seis possuem ao menos um município litorâneo (Polo São Luís, Polo

ção se deem nesses espaços, sem, contudo, representarem um uso hegemônico do território, como é o caso de camponeses, quilombolas etc. (Cf. COSTA, 2015). 
Munim, Polo Parque dos Lençóis Maranhenses, Polo Delta das Américas, Polo Floresta dos Guarás e Polo Amazônia Maranhense).

Dentre os polos selecionados como prioritários, destacam-se o Parque dos Lençóis Maranhenses, o Delta das Américas e o de São Luís, evidenciando uma concentração da atividade no Litoral Oriental, aproveitando-se os resultados obtidos com o Plano Maior na indução da atividade na região dos Lençóis Maranhenses. Permanece assim a prioridade de indução ao turismo litorâneo como parte das estratégias de vinculação às políticas regionais e nacionais - e suas formas de captação de recursos e financiamentos. É o litoral o espaço eleito para o uso turístico por excelência e suas áreas não exploradas são chamadas a exercer seu papel na expansão do uso turístico do território.

Os polos com municípios litorâneos são apresentados destacando seu potencial para o ecoturismo, sem abrir mão do turismo de sol e praia. Os polos São Luís e Barreirinhas aparecem como aqueles que reúnem os principais atrativos e as melhores infraestruturas para a atividade no litoral do estado, sendo considerados indutores do desenvolvimento turístico no Maranhão. Os polos Delta das Américas e Floresta dos Guarás são apontados como polos estratégicos por suas potencialidades para o ecoturismo. O primeiro, articulado à Rota das Emoções, o segundo incluído como polo do Proecotur no Maranhão, sendo destacadas suas características amazônicas. Neste mesmo sentido, o polo Amazônia Maranhense aparece como um espaço a ser desenvolvido enquanto atrativo para a atividade com base na reafirmação de certa "amazonidade maranhense", da experiência na "Amazônia nordestina" (MARANHÃO 2012).

O governo do estado se propõe, diante do intuito de expandir o uso turístico do território, a enfrentar os problemas diagnosticados (divulgação, preços elevados, acessibilidade, etc.) e estruturar o turismo de sol e praia em praticamente todo o litoral do Maranhão.

A expansão do turismo litorâneo em curso no Maranhão se manifesta de modo desigual, respondendo à seletividade espacial característica da atividade, em grande parte ligada às induções estatais e opções de planejamento na estruturação dos destinos e sua divulgação. A manutenção de espaços para futura exploração aparece como a garantia do "novo", espaço "a descobrir", elementos que alimentam o turismo e os turistas na busca por novos lugares.

Destaca-se, dessa maneira, uma expansão do turismo que se dá no litoral do estado a partir do eixo São Luís-Alcântara e que se estende, após meados da década de 1990, para a área do Parque Nacional dos
Lençóis Maranhenses e seu entorno. Esta área se consolida como polo turístico do estado, direcionando investimentos e fluxos turísticos, intensificados ao longo da primeira década do século XXI e responsáveis por parcela considerável da atividade desenvolvida no Maranhão. A elaboração do Plano Maior 2020 reforça a intenção de expansão da atividade turística para outros pontos do litoral do estado já manifestada em sua primeira versão do fim da década de 1990. Nesse sentido, intensifica o propósito de direcionar fluxos ao Litoral Ocidental, destacando sua condição amazônica, induzindo o potencial dos polos Florestas dos Guarás e Amazônia Maranhense.

Diante disso, a expansão do uso turístico do litoral do Maranhão se dá em um processo de apropriação de espaços até então não vinculados a esta atividade, incorporados como fundos territoriais para o turismo, tornados mercadoria. Os municípios litorâneos passam a buscar instrumentos normativos e de gestão que possibilitem o desenvolvimento da atividade, seguindo as possibilidades de captação de recursos e incentivos apontados pelos governos estadual e federal. O governo do estado propõe "um caminho a ser seguido com o objetivo de conquistar os mercados mundiais e atrair visitantes9', visando colocar o Maranhão "entre os grandes destinos mundiais" (MARANHÃO 2011, p. 03). A pesquisa de campo realizada nos municípios litorâneos do estado, entretanto, demonstrou profundas dificuldades para isso. As dificuldades de acesso, as precárias infraestruturas e a situação de pobreza da maior parte dos lugares postos à descoberta dificultam a priorização de investimentos em turismo e destoam daquilo que é destacado nos planos e folders de divulgação turística.

Mesmo assim, percebe-se a inserção da atividade em considerável parte dos municípios do litoral do Maranhão, embora em sua larga maioria esta atividade ainda não seja considerada uma das principais, destacando-se predominantemente a pesca e a agricultura. A expansão do turismo é perceptível, tendo sido constatada nas observações efetuadas no campo e em entrevistas realizadas com gestores, moradores dos municípios litorâneos e empresários.

As desigualdades territoriais desse processo respondem aos vetores de expansão induzidos pelo Estado. A hierarquia estabelecida entre os polos (Indutores, Estratégicos e de Desenvolvimento) canaliza recursos e estabelece prioridades em desigualdade, além de apontar certas áreas como mais importantes para a expansão do

\footnotetext{
9“Em 1999, o Plano Maior estabeleceu a meta de o Estado receber 1,5 milhão de turistas em 2010, sendo $80 \%$ nacionais e $20 \%$ estrangeiros. Em 2009, o Estado ultrapassou essa meta, recebendo 1,7 milhão de turistas" (MARANHÃO 2011 p. 07).
} 
uso turístico do litoral.

Em alguns municípios, como é o caso de Barreirinhas, as estratégias de expansão promovidas pelo governo do estado a partir dos planos já manifestam resultados materializados em fluxos e investimentos mais volumosos, bem como em impactos e conflitos. Ao mesmo tempo, outros municípios litorâneos do estado, como Carutapera e Guimarães, são apontados como espaços importantes para a expansão, mas a atividade nesses municípios se desenvolve de modo muito embrionário, configurando-os como fundos territoriais para o turismo no litoral do Maranhão, cuja apropriação compõe a estratégia de expansão da atividade.

Estes polos estão segmentados em Polos Indutores (São Luís, Parque dos Lençóis Maranhenses e Chapada das Mesas), Polos Estratégicos (Floresta dos Guarás, Delta das Américas, Munim e Lagos e Campos floridos) e Polos de Desenvolvimento (Amazônia Maranhense, Cocais e Serras, Guajajara, Timbira e Kanela).

Tal distribuição hierárquica das categorias dos polos indica vetores de expansão da atividade que, embora não lineares, posicionam os municípios do Litoral Ocidental como espaços de expansão (Floresta dos Guarás como polo estratégico, em condição intermediária entre os polos indutores e os polos de desenvolvimento, classe em que se situa o polo Amazônia Maranhense), fundos territoriais para o turismo em vias de incorporaçã $q^{10}$ Os polos indutores são aqueles que apresentam "capacidade de obter a máxima rentabilidade a partir da melhor otimização da oferta atual e dos produtos existentes" em curto e médio prazos. Por sua vez, os polos estratégicos são considerados importantes para "a diversificação da oferta em médio prazo", tanto por seus potenciais quanto por questões de acessibilidade, enquanto os polos de desenvolvimento são apontados como áreas para investimentos a longo prazo, requerendo indução de investimentos e divulgação, porém "em cenários orçamentários limitados" (MARANHÃO. 2012, p. 184).

$\mathrm{Na}$ referida proposta retornam a figurar como áreas destinadas ao uso turístico do território a região da Baixada Maranhense e dos Cocais, sendo incluído ainda um polo vinculado à cultura indígena. Embora sejam

\footnotetext{
${ }^{10}$ Compreendemos aqui o conceito de fundos territoriais como espaços sem "uso hegemônico", onde o uso capitalista do território não é hegemônico ou não atende às necessidades de acumulação vigente no plano das relações capitalistas. Configuram-se, portanto, como uma espécie de estoque territorial para a expansão da acumulação de capital, embora possam conter usos não propriamente capitalistas ou apenas estarem sob domínio passível de apropriação. Tal pressuposto não exclui a existência de grupos sociais cujas relações de reprodução se deem nesses espaços, sem, contudo, representarem um uso hegemônico do território, como é o caso de camponeses, quilombolas etc. (Cf. (COSTA 2015).
}

propostos novos polos no interior do território, priorizase ainda o desenvolvimento do turismo no litoral, concentrando a maior parte dos polos turísticos no espaço litorâneo. Dos dez polos estabelecidos, seis possuem ao menos um município litorâneo (Polo São Luís, Polo Munim, Polo Parque dos Lençóis Maranhenses, Polo Delta das Américas, Polo Floresta dos Guarás e Polo Amazônia Maranhense).

Dentre os polos selecionados como prioritários, destacam-se o Parque dos Lençóis Maranhenses, o Delta das Américas e o de São Luís, evidenciando uma concentração da atividade no Litoral Oriental, aproveitando-se os resultados obtidos com o Plano Maior na indução da atividade na região dos Lençóis Maranhenses. Permanece assim a prioridade de indução ao turismo litorâneo como parte das estratégias de vinculação às políticas regionais e nacionais - e suas formas de captação de recursos e financiamentos. É o litoral o espaço eleito para o uso turístico por excelência e suas áreas não exploradas são chamadas a exercer seu papel na expansão do uso turístico do território.

Os polos com municípios litorâneos são apresentados destacando seu potencial para o ecoturismo, sem abrir mão do turismo de sol e praia. Os polos São Luís e Barreirinhas aparecem como aqueles que reúnem os principais atrativos e as melhores infraestruturas para a atividade no litoral do estado, sendo considerados indutores do desenvolvimento turístico no Maranhão. Os polos Delta das Américas e Floresta dos Guarás são apontados como polos estratégicos por suas potencialidades para o ecoturismo. O primeiro, articulado à Rota das Emoções, o segundo incluído como polo do Proecotur no Maranhão, sendo destacadas suas características amazônicas. Neste mesmo sentido, o polo Amazônia Maranhense aparece como um espaço a ser desenvolvido enquanto atrativo para a atividade com base na reafirmação de certa "amazonidade maranhense", da experiência na "Amazônia nordestina" (MARANHÃO. 2012) (MARANHÃO, 2012).

O governo do estado se propõe, diante do intuito de expandir o uso turístico do território, a enfrentar os problemas diagnosticados (divulgação, preços elevados, acessibilidade, etc.) e estruturar o turismo de sol e praia em praticamente todo o litoral do Maranhão.

A expansão do turismo litorâneo em curso no Maranhão se manifesta de modo desigual, respondendo à seletividade espacial característica da atividade, em grande parte ligada às induções estatais e opções de planejamento na estruturação dos destinos e sua divulgação. A manutenção de espaços para futura exploração aparece como a garantia do "novo", espaço "a descobrir", elementos que alimentam o turismo e os turistas 
na busca por novos lugares.

Destaca-se, dessa maneira, uma expansão do turismo que se dá no litoral do estado a partir do eixo São Luís-Alcântara e que se estende, após meados da década de 1990, para a área do Parque Nacional dos Lençóis Maranhenses e seu entorno. Esta área se consolida como polo turístico do estado, direcionando investimentos e fluxos turísticos, intensificados ao longo da primeira década do século XXI e responsáveis por parcela considerável da atividade desenvolvida no Maranhão. A elaboração do Plano Maior 2020 reforça a intenção de expansão da atividade turística para outros pontos do litoral do estado já manifestada em sua primeira versão do fim da década de 1990. Nesse sentido, intensifica o propósito de direcionar fluxos ao Litoral Ocidental, destacando sua condição amazônica, induzindo o potencial dos polos Florestas dos Guarás e Amazônia Maranhense.

Diante disso, a expansão do uso turístico do litoral do Maranhão se dá em um processo de apropriação de espaços até então não vinculados a esta atividade, incorporados como fundos territoriais para o turismo, tornados mercadoria. Os municípios litorâneos passam a buscar instrumentos normativos e de gestão que possibilitem o desenvolvimento da atividade, seguindo as possibilidades de captação de recursos e incentivos apontados pelos governos estadual e federal. O governo do estado propõe "um caminho a ser seguido com o objetivo de conquistar os mercados mundiais e atrair visitantes 11, visando colocar o Maranhão "entre os grandes destinos mundiais” (MARANHÃO, 2011, p. 03). A pesquisa de campo realizada nos municípios litorâneos do estado, entretanto, demonstrou profundas dificuldades para isso. As dificuldades de acesso, as precárias infraestruturas e a situação de pobreza da maior parte dos lugares postos à descoberta dificultam a priorização de investimentos em turismo e destoam daquilo que é destacado nos planos e folders de divulgação turística.

Mesmo assim, percebe-se a inserção da atividade em considerável parte dos municípios do litoral do Maranhão, embora em sua larga maioria esta atividade ainda não seja considerada uma das principais, destacando-se predominantemente a pesca e a agricultura. A expansão do turismo é perceptível, tendo sido constatada nas observações efetuadas no campo e em entrevistas realizadas com gestores, moradores dos municípios litorâneos e empresários.

As desigualdades territoriais desse processo respon-

11 "Em 1999, o Plano Maior estabeleceu a meta de o Estado receber 1,5 milhão de turistas em 2010 , sendo $80 \%$ nacionais e $20 \%$ estrangeiros. Em 2009, o Estado ultrapassou essa meta, recebendo 1,7 milhão de turistas" (MARANHÃO 2011 p. 07). dem aos vetores de expansão induzidos pelo Estado. A hierarquia estabelecida entre os polos (Indutores, Estratégicos e de Desenvolvimento) canaliza recursos e estabelece prioridades em desigualdade, além de apontar certas áreas como mais importantes para a expansão do uso turístico do litoral.

Em alguns municípios, como é o caso de Barreirinhas, as estratégias de expansão promovidas pelo governo do estado a partir dos planos já manifestam resultados materializados em fluxos e investimentos mais volumosos, bem como em impactos e conflitos. Ao mesmo tempo, outros municípios litorâneos do estado, como Carutapera e Guimarães, são apontados como espaços importantes para a expansão, mas a atividade nesses municípios se desenvolve de modo muito embrionário, configurando-os como fundos territoriais para o turismo no litoral do Maranhão, cuja apropriação compõe a estratégia de expansão da atividade.

\section{CONSIDERAÇÕES FINAIS}

Para o turismo, o território do Maranhão está circunscrito prioritariamente ao litoral. Acompanhando a predominância da apropriação dos espaços litorâneos para as atividades de lazer e adotando a perspectiva da expansão da atividade turística no contexto de sua dispersão geográfica - na busca por novos destinos para os fluxos turísticos - o Estado direciona para o litoral do Maranhão sua intenção de implementação de um uso turístico do território como parte das novas possibilidades de acumulação a serem exploradas na periferia do Brasil.

O mencionado processo tem avançado nas últimas décadas sobre espaços até então sem uso turístico expressivo. Nesse contexto, o turismo se expande, espraiando-se a partir da região Nordeste em direção ao litoral norte do país, impulsionado pela indução estatal de investimentos justificados por um potencial associado às "características amazônicas", às possibilidades de exploração de Unidades de Conservação pelo ecoturismo, ao encontro de características naturais diversas, tudo isso transformado em produtos turísticos, devidamente dispostos para o consumo.

O Estado atua normatizando o uso do território, induzindo formas específicas de exploração aos lugares buscando a efetivação desses usos mediante a incorporação de novos espaços para a aplicação de capitais. Para isso dispõe de canais de financiamento e recursos próprios para a aplicação na produção das condições necessárias ao funcionamento das dinâmicas estabelecidas como prioritárias. Utiliza-se para isso de planos, programas, projetos, leis e demais instrumentos normativos, além de canalizar parte de seu capital ao atendi- 
mento dessas necessidades mediante o aparelhamento de instituições financeiras a isso dedicadas.

O litoral do Maranhão é, assim, aberto ao mercado turístico, disponível a agentes ávido por novas oportunidades de negócio e investimentos, explorações e especulações lucrativas.

\section{REFERÊNCIAS}

BANDEIRA, I. C. N. Geodiversidade do Estado do Maranhão. Teresina: CPRM, 2013.

COSTA, C. R. R. d. O litoral do Maranhão, entre segredos e descobertas: a fronteira de expansão do turismo litorâneo na periferia do Brasil. Tese (Doutorado em Geografia Humana) — Departamento de Geografia, Faculdade de Filosofia, Letras e Ciências Humanas, Universidade de São Paulo, São Paulo, 2015 .

COSTA, W. C. d. Sob o signo da morte: o poder oligárquico de Victorino a Sarney. São Luís: Edufma, 2006.

FERREIRA, A. J. d. A. O turismo e a produção do espaço no estado do Maranhão, Brasil. In: Actas del IX Coloquio Internacional de Geocrítica. Porto Alegre: Universidade Federal do Rio Grande do Sul, 2007. Disponível em: <<http://www.ub.edu/geocrit/9porto/antonfer.htm >> Acesso em: 13 de janeiro de 2010.

GONÇALVES, M. d. F. d. C. A reinvenção do Maranhão Dinástico. São Luís: Edições UFMA/PROIN-CS, 2000.

A invenção de uma rainha de espada: reatualizações e embaraços na dinâmica política do Maranhão Dinástico. São Luís: Edufma, 2008.

LOBATO, F. M. Descentralização das Políticas Públicas de Turismo: a municipalização do turismo no Maranhão. Dissertação (Mestrado em Ciências da Comunicação) - Departamento de Relações Públicas, Propaganda e Turismo. Escola de Comunicação e Artes. Universidade de São Paulo, São Paulo, 2001.

MARANHÃ. Secretaria de Turismo. Pesquisa de demanda turística. Relatório São Luís, São Luís: SETUR-MA, 2011.

MARANHÃO. Governo do Estado do Maranhão. Plano de Desenvolvimento Turístico do Estado do Maranhão, São Luís, 1972.
. Empresa Maranhense de Turismo S.A. MARATUR. Subsídios para a história do turismo no Maranhão, São Lmuís: MARATUR, 1982.

Gerência de Planejamento e Desenvolvimento Econômico. Plano de Desenvolvimento Integral do Turismo do Maranhão: plano maior, São Luís: GEPLAN, 2000.

Secretaria de Turismo. Plano estratégico de Turismo do Estado do Maranhão: Plano Maior 2020. Informe Executivo, São Luís: SETUR-MA, 2011.

Secretaria de Turismo. Plano maior 2020 Plano Estratégico de Turismo do Estado do Maranhão. Relatório Final, São Luís: SETUR-MA, 2012.

Secretaria de Turismo. Plano de Desenvolvimento Integrado do Turismo Sustentável - PDITS da Área Turística de São Luís. Produto 5 - Versão preliminar, São Luís: SETUR-MA, 2014.

MORAES, A. C. R. Ideologias geográficas: espaço, cultura e política no Brasil. São Paulo: Annablume, 2005, 2005. 